\title{
Carbon nanotube buckypaper reinforced polymer composites: a review
}

\author{
Bruno Ribeiro ${ }^{1 *}$, Edson Cocchieri Botelho ${ }^{1}$, Michelle Leali Costa ${ }^{1}$ and Cirlene Fourquet Bandeira1 \\ 'Departamento de Materiais e Tecnologia, Universidade Estadual Paulista “Júlio de Mesquita Filho" - \\ UNESP, Guaratinguetá, SP, Brazil \\ *dorado.bruno@gmail.com
}

\begin{abstract}
This review provides valuable information about the general characteristics, processing conditions and physical properties of carbon nanotube buckypaper (BP) and its polymer composites. Vacuum filtration is the most common technique used for manufacturing BP, since the carbon nanotubes are dispersed in aqueous solution with the aid of surfactant. Previous works have reported that mechanical properties of BP prepared by vacuum filtration technique are relatively weak. On the other hand, the incorporation of polymer materials in those nanostructures revealed a significant improvement in their mechanical behavior, since the impregnation between matrix and BP is optimized. Electrical conductivity of BP/polymer composites can reach values as high as $2000 \mathrm{~S} / \mathrm{m}$, which are several orders of magnitude greater than traditional CNT/polymer composites. Also, BP can improve remarkably the thermal stability of polymer matrices, opening new perspectives to use this material in fire retardant applications.
\end{abstract}

Keywords: BP composites, carbon nanotubes buckypaper, physical properties.

\section{Introduction to CNTs}

Since the Discovery of carbon nanotubes (CNTs) in 1991 by Iijima, CNTs have attracted a great deal of interest due to their superior mechanical, electrical and thermal properties, which makes them an ideal candidate of nanofiller in preparation of polymer nanostructured composites ${ }^{[1-4]}$. The possibility of obtaining advanced composites with multifunctional properties has attracted the efforts of researches in both industry and academia. Industry assumes their potential applications such as nanoelectronics devices and ultra-light structural materials. Since the first report of synthesis of polymer nanostructured composites by Ajayan in $1994^{[5]}$, the number of research articles related to CNTs reinforced polymer composites has increased exponentially, with more than 2000 publications in $2010^{[6]}$. On the other hand, one of the limitations for industrial application of CNTs is their high price in relation to polymer value. This barrier can be overcome when CNTs provide significant improvement in properties of high performance polymers for high-end applications $^{[7-9]}$.

A carbon nanotube can be defined as cylinders composed of rolled-up graphite planes with diameters in nanometer scale. Although similar in chemical composition to graphite, CNTs are highly isotropic, and it is this topology that distinguishes nanotubes from other carbon structures and gives them their unique properties. Also, they are one dimensional carbon material which have an aspect ratio greater than $100^{[3,10-12]}$. There are basically two main kinds of CNTs: single walled carbon nanotubes (SWCNT) and multi walled carbon nanotubes (MWCNT) as illustrated in Figure 1. The first one consists of a single graphene layer rolled up into a seamless cylinder, and its diameter is around $0.5-1.5 \mathrm{~nm}^{[14]}$. On the other hand, MWCNTs is defined by two or more concentric cylindrical shells of graphene sheets coaxially arranged around a central hollow core with van der Waals forces between adjacent layers ${ }^{[15]}$.
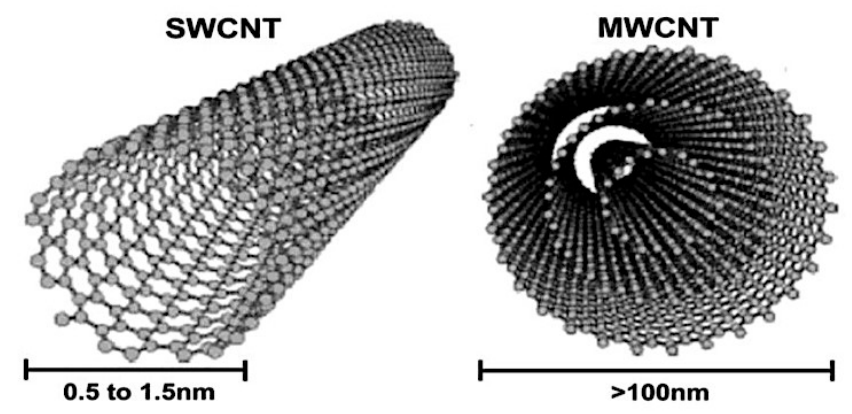

Figure 1. Schematic representation of single walled carbon nanotube (SWCNT) and multi walled carbon nanotube (MWCNT) ${ }^{[13]}$. 


\section{Properties of CNTs}

The physical properties of CNTs are compared to other carbon materials such as graphite, diamond and fullerene in Table 1. According to the literature ${ }^{[3,16,17]}$ quantum mechanics calculations can predict remarkable mechanical properties for SWCNTs. Theoretical and experimental results have demonstrated unusual mechanical properties of SWCNTs with Young's modulus as high as 1TPa and tensile strength of 150-180 GPa. Byrne and Gun' $\mathrm{ko}^{[18]}$ reported in their work that measured Young's moduli for individual MWCNTs of between 0.27-0.95 TPa and strengths in the 11-63 GPa range. These make CNTs the strongest and stiffest materials on earth.

Adding carbon fillers to polymers in order to improve mechanical properties and decrease weight is not a novel idea. Carbon black has been utilized to reinforce rubber and plastics ${ }^{[19,20]}$. Also, carbon fibers composites are very popular materials that have been used in airplanes, cars, bicycles, etc $^{[21]}$. However, the great potential of CNTs makes them crucial materials to obtain new nanostructured products with remarkable mechanical features. For example, sports equipment, such as tennis racquets containing CNTs, have been produced and marketed. With CNTs becoming easier to produce and cheaper to buy, the CNT industry could potentially overtake that of the carbon fiber industry and become one of the major additives for polymer-composite fabrication ${ }^{[18,22,23]}$.

Similar to mechanical properties, electrical conductivity of CNTs are quite varied, probably due to varying levels of defects as well as an unknown distribution of chiralities. According to previous works ${ }^{[15]}$, MWCNTs show both a metallic and semiconducting behaviors, with conductivities raging from $2 \times 10^{7}$ to $8 \times 10^{5} \mathrm{~S} / \mathrm{m}$. In addition, the electrical conductivity of SWCNTs can be calculated as about $5 \times 10^{7} \mathrm{~S} / \mathrm{m}$. An interesting electrical application of CNTs is their ability to work as field emitters. Field emission is a property by which a material can be induced to eject electrons simply by putting a voltage difference between it and an object. Carbon nanotubes are excellent field emitters because of their highly anisotropic nature and their small diameter.

Thermal conductivity is another property of CNTs that has been attracting great attention by several researches. Theory predicts that MWCNTs presents thermal conductivity as high as $3000 \mathrm{~W} / \mathrm{mK}$ at room temperature, which is higher than that found for cooper $(385 \mathrm{~W} / \mathrm{mK})^{[10,12,15,18]}$. On the other hand, experimental studies ${ }^{[24,25]}$ found thermal conductivity at room temperature to be significantly lower, $300 \mathrm{~W} / \mathrm{m} \mathrm{K}$, for a single MWCNT. Simulations reveal that thermal conductivity should depend on nanotube length, increasing as nanotubes become longer. Also, obtaining measurements of this property is very difficult, since the simulations suggest nanotubes can interact with a substrate causing a reduction in the thermal conductivity ${ }^{[10,15]}$.

Table 1. Physical properties of different carbon nanotubes ${ }^{[10]}$.

\begin{tabular}{ccc}
\hline Property & SWCNT & MWCNT \\
\hline Density $\left(\mathrm{g} / \mathrm{cm}^{3}\right)$ & 0.8 & 1.8 \\
Electrical conductivity $(\mathrm{S} / \mathrm{cm})$ & $10^{2}-10^{6}$ & $10^{3}-10^{5}$ \\
Thermal conductivity $(\mathrm{W} / \mathrm{mK})$ & 6000 & 2000 \\
Thermal stability in air $\left({ }^{\circ} \mathrm{C}\right)$ & $>600$ & $>600$ \\
\hline
\end{tabular}

\section{Dispersion of CNTs}

The successful utilization of CNTs in composite applications depends on their homogenous dispersion throughout the polymer matrix. After several years of research, the full potential of CNTs as reinforcements has been limited due to the issues associated with dispersion of entangled CNT during processing and poor interfacial interaction between nanofillers and polymer matrix ${ }^{[26-29]}$. Carbon nanotubes have a tendency to form agglomerates during synthesis because of van der Waals attraction between nanotubes, leading in most cases to the formation of large agglomerates in polymer matrices, as can be seen in Figure 2. It has been proved that these bundles and agglomerates result in diminished mechanical, thermal and electrical properties of composites as compared with theoretical predictions related to individual $\mathrm{CNTs}^{[31-33]}$. Also, the processability of CNT-based composites, especially with thermoplastic matrix is not an easy task, since the high aspect ratio $(>1000)$ is responsible for a substantial increase in viscosity of polymer, thus affecting its dispersion process. Such a behavior has been considered as one of the great challenges in obtaining CNT reinforced polymer composites, because its use is generally limited to levels lower than $5 \% \mathrm{vol}$ in the polymer matrix ${ }^{[12,30]}$.

Ultrasonication is a technique that consists in applying ultrasound energy to agitate particles in a solution. It is the most frequently used method for nanoparticle dispersion. The equipment called sonicator (Figure 3 ) produces shock waves that promotes "peeling off" of individual nanoparticles located at the outer part of the nanoparticle bundles, or agglomerates, and thus results in the separation of individualized nanoparticles from the bundles ${ }^{[10]}$. This technique has been employed to disperse CNTs in liquids with low viscosity, such as water, ethanol and acetone.

However, the sonication treatment plays a crucial role during the dispersion process. If it is aggressive and/or too long, CNTs can be easily damaged, especially when a probe sonicator is employed. The localized damage to nanotubes deteriorates both electrical and mechanical properties of the CNT reinforced polymer composites ${ }^{[35-37]}$.

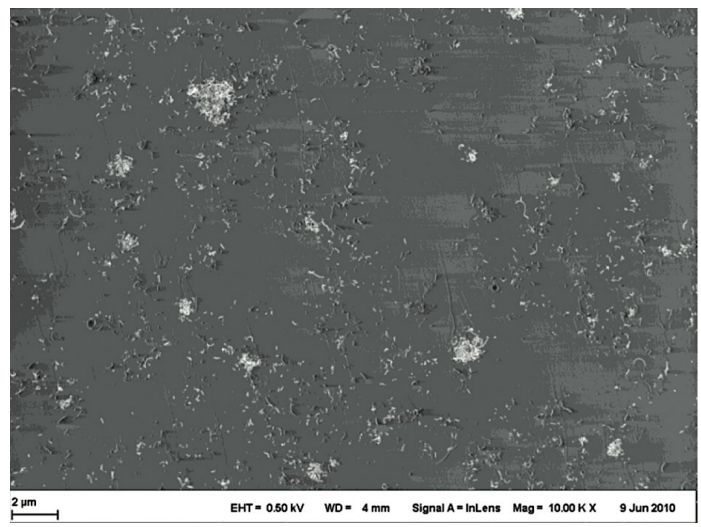

Figure 2. SEM images from fractured surfaces of phenolic resin/ CNT composites ${ }^{[30]}$. 


\section{Functionalization of CNTs}

In the last decade the chemical modification of CNTs has been the focus on intense research in the scientific community. As previously mentioned in this work, CNTs exist in clusters due to van der Waals interactions that make difficult their dispersion in polymer matrix. Therefore, a major challenge in the development of nanostructured polymer composites is to obtain a satisfactory dispersion of the filler in the polymer matrix in order to maximize the properties of the final product. Also, the functionalization process appears to prevent agglomeration of the $\mathrm{CNT}$, improving the interfacial adhesion between polymer and reinforcement. Basically, the functionalization process can be divided in two groups: covalent and non-covalent functionalization, which is described below. Table 2 provides advantages and disadvantages of functionalization techniques.

\subsection{Covalent functionalization}

Covalent functionalization of CNTs can be achieved by either direct addition reactions of reagents to the sidewalls of nanotubes or modification of appropriate surface-bound functional groups on the nanotubes ${ }^{[29,38]}$. The most common method employed to functionalize CNTs covalently is nanotube

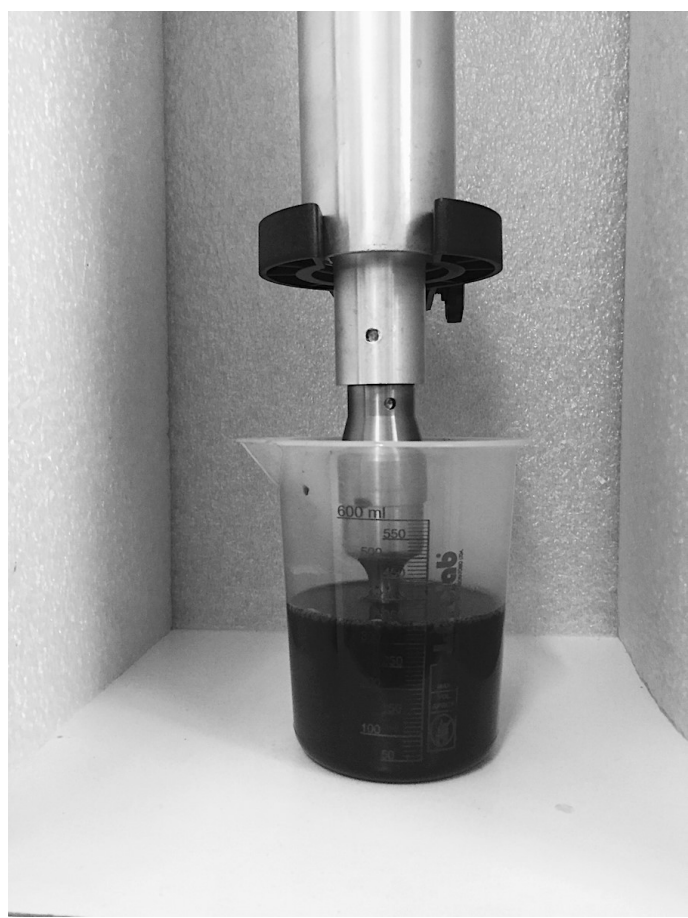

Figure 3. Sonication tip dispersing carbon nanotubes in aqueous solution $^{[34]}$. oxidation, which results in the formation of carboxylic acid groups $(-\mathrm{COOH})$ on the surface of the nanotubes. During the process, CNTs are refluxed with a mixture of inorganic acids $\left(\mathrm{H}_{2} \mathrm{SO}_{4} / \mathrm{HNO}_{3}\right)$, sometimes with the application of high power sonication. This functionalization provides stables dispersions of CNTs in a range of polar solvents, including water ${ }^{[38-41]}$. The functionalization reaction is exemplified in Figure 4.

However, there are some issues during the covalent functionalization that have been reported. The employment of concentrated inorganic acids combined with high power sonication is responsible for creating a large number of defects on the CNTs sidewalls, and in some extreme cases, CNTs are fragmented into smaller pieces. These damaging effects can result in severe degradation of mechanical, electrical and thermal properties of $\mathrm{CNTS}^{[10,12]}$

\subsection{Non-covalent functionalization}

Non-covalent functionalization is an alternative method for improving the interfacial properties of nanotubes. Also, the process normally involves van der Waals, $\pi-\pi$ or $\mathrm{CH}-\pi$ interactions between polymer molecules and CNT surface ${ }^{[42-44]}$. The two major approaches for non-covalent functionalization is polymer wrapping and surfactant-assisted dispersion.

A typical non-covalent functionalization is known as polymer wrapping. In this case, the suspension of CNTs in the presence of polymers, such as polystyrene ${ }^{[45]}$ or poly(ether-imide) $)^{[46]}$, lead to the wrapping of polymer around the CNTs to form supermolecular complexes of CNTs. The polymer wrapping process is achieved through the van der Waals interactions and $\pi-\pi$ stacking between CNTs and polymer chains containing aromatic rings.

Surfactant-assisted dispersion consists to transfer CNTs to aqueous phase with the aid of surface-active molecules such as sodium dodecyl-sulfate (SDS) or polyoxyethylene

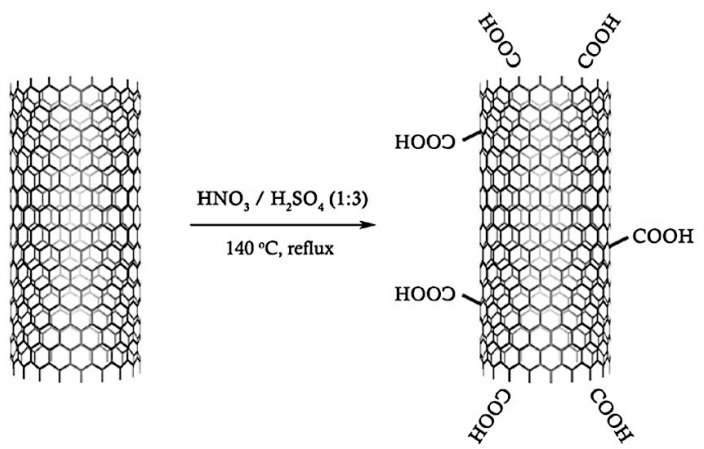

Figure 4. Covalent functionalization reaction of carbon nanotubes ${ }^{[41]}$

Table 2. Characteristics of different CNT functionalization techniques ${ }^{[10]}$.

\begin{tabular}{|c|c|c|c|c|}
\hline Functionalization & & Damage to CNTs & $\begin{array}{c}\text { Interaction with } \\
\text { polymer }\end{array}$ & $\begin{array}{l}\text { Re-agglomeration of } \\
\text { CNTs in matrix }\end{array}$ \\
\hline Covalent & Incorporation of functional groups & Yes & Strong & Yes \\
\hline \multirow[t]{2}{*}{ Non-covalent } & Polymer wrapping & No & Variable & No \\
\hline & Surfactant adsorption & No & Weak & No \\
\hline
\end{tabular}


octyl phenyl ether (Triton X-100). The physical adsorption of surfactant on the nanotubes surface reduces the surface tension of CNTs, effectively preventing the formation of aggregates. Also, the presence of an aromatic group in the surfactant molecule allows for $\pi-\pi$ stacking interactions with the graphitic sidewalls of the nanotubes, which results in their effective coating and dispersion ${ }^{[47,48]}$.

The advantage of using non-covalent functionalization is that it does not alter the structure of the nanotubes and, therefore, both electrical and mechanical properties remain unchanged. However, the efficiency of the load transfer might decrease since the forces between the wrapping molecules and the nanotube surface might be relatively weak ${ }^{[10,18,39,44]}$.

\section{CNT buckypaper reinforced polymer composites}

Polymer composites, consisting of additives and polymer matrices, including thermoplastics, thermosets and elastomers, are considered to be an important group of relatively inexpensive materials for many engineering applications. As effective nanoscale reinforcement, CNTs have attracted great interests in the field of polymer composites. These nanomaterials displays good mechanical properties, excellent electrical and thermal conductivities, which are considered remarkable attributes for many applications in several fields of industry. However, as previously discussed in this work, their low solubility in common solvents, strong agglomerating tendency and high viscosity of CNT/polymer mixtures caused a poor dispersion and limited their practical applications. In order to solve this issues, CNT sheets, also known as buckypapers (BPs) have been employed to development of polymer nanostructured composites. BPs can be defined as a free-standing porous mats of entangled CNT ropes cohesively bounded by van der Waals interactions ${ }^{[49-52]}$. Consequently, this material is used in diverse applications such as artificial muscles ${ }^{[53]}$, electrodes ${ }^{[54]}$, field-emission ${ }^{[55]}$, fire shields ${ }^{[5]}$, and for water purification $^{[57]}$. Also, BPs can be used to prepare polymer composites with uniform tube dispersion, controlled nanostructure and high CNT loading (up to $60 \mathrm{wt} \%$ ) $^{[58]}$.
The most common technique used for manufacturing BPs is vacuum filtration. The procedure involves basically three steps. Firstly, a small amount of CNTs is ultrasonically dispersed in a solvent with the assistance of a surfactant. The most common solvents used to prepare BPs with good quality are N-Methylpyrrolidone (NMP) and N,N-dimethylformamide (DMF ${ }^{[59]}$. However, using an appropriate surfactant in water can be cheaper than using DMF and NMP, which also exhibit the disadvantage of high boiling points. Sodium dodecyl-sulfate (SDS) and polyoxyethylene octyl phenyl ether (Triton X-100) have been employed as water based surfactants for manufacturing BPs by several researches ${ }^{[60,61]}$. On the second step, a vacuum-assisted filtration of a homogeneously dispersed CNT solution is carried out, using a polytetrafluoroethylene or nylon filter with submicron-sized pores. Finally, CNTs are deposited on the filter surface and form a thin membrane (buckypaper) that can be removed from the filter after drying. Figure 5 shows the buckypaper obtained by vacuum filtration technique.

The major differences between conventional CNT/polymer composites and those incorporating BPs are the carbon content, the bundle distribution and the manufacturing process. Dispersed CNT reinforced composites are usually prepared by melt-mixing ${ }^{[62]}$, mixing solution ${ }^{[63]}$ or in situ polymerization ${ }^{[64]}$. Also, their carbon content is generally lower than $5 \mathrm{wt} . \%$ and the nanotube bundles are dispersed through the matrix without forming a network. On the other hand, BP composites are manufactured by techniques such as hot-compression ${ }^{[65]}$, electro-spinning ${ }^{[66]}$, and intercalation ${ }^{[67]}$. These materials usually have carbon content higher than $30 \mathrm{wt} . \%$ resulting in a network, which acts as a skeleton. Also, higher mechanical, electrical and thermal properties of the composites could be expected, as a result of better transfer of stress, electrons and phonons of the CNT networks.

\subsection{Properties of BP/polymer composites}

The properties of buckypaper and its polymer composites have been attracted great attention of academic community. Wide variations are reported in the properties, especially mechanical properties of BP/polymer composites. The mechanical
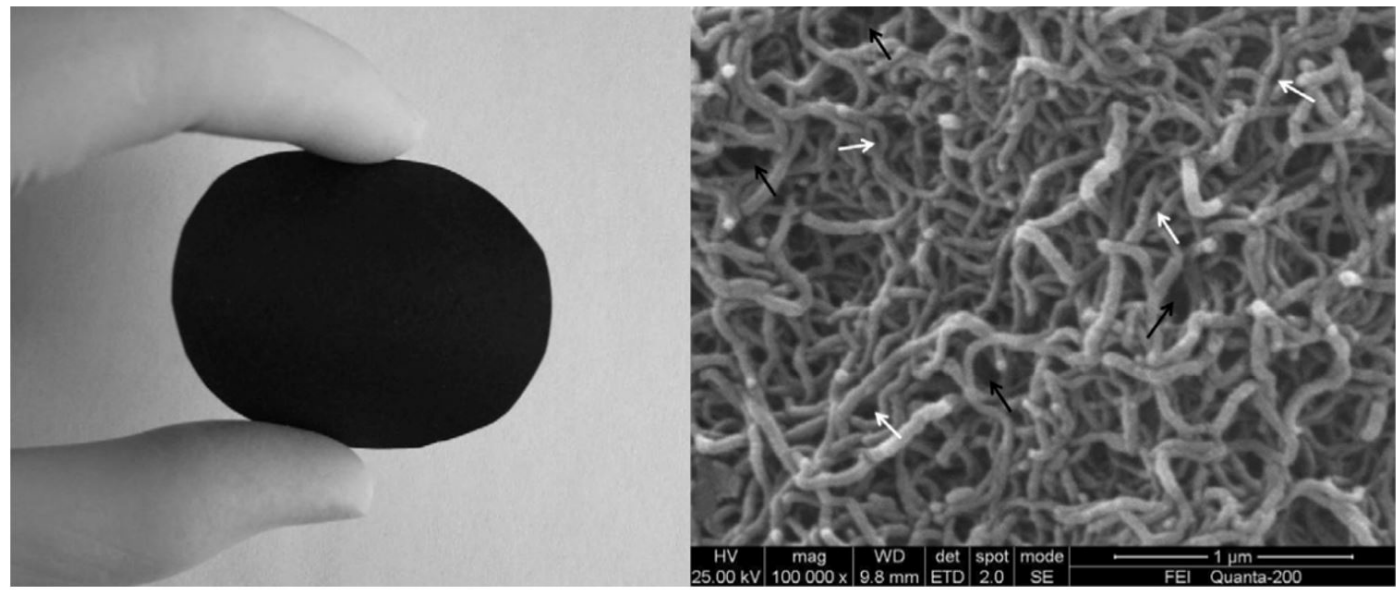

Figure 5. Representation of MWCNT buckypaper and its microstructure observed by SEM ${ }^{[61]}$. 
properties of BPs prepared by vacuum filtration technique are relatively weak, leading to a Young's modulus and a tensile strength of $0.2-2 \mathrm{GPa}$ and 2-33 MPa, respectively ${ }^{[68-72]}$. However, when polymer matrices are incorporated into BPs these properties display a significant improvement. Han et al. ${ }^{[73]}$ in a study of $\mathrm{BP} /$ polyurethane composites reported that both Young's modulus and tensile strength increase dramatically by $340 \%$ and $960 \%$, respectively, as MWCNT loading reach $46 \mathrm{vol} \%$. These improvements were compared to neat BPs prepared by the authors. Similar results were found by Pham et al. ${ }^{[58]}$ in a study of BP/polycarbonate composites, since the Young modulus and tensile strength increased by about 120 and $200 \%$, respectively. Also, the mechanical properties of $\mathrm{BP} /$ polymer composites can be highly influenced by the processing technique employed during the consolidation of the material. Ashrafi et al. ${ }^{[74]}$ compared the correlation between Young's modulus and impregnation quality of SWCNT BP/epoxy composites. They found Young's modulus as high as $11.4 \mathrm{GPa}$ when vacuum technique was employed, whereas for hot-press composites this value was $3.5 \mathrm{GPa}$. This behavior can be attributed to a higher quality of impregnation as well as a higher content (40-45 wt.\%) of CNT than other buckypaper composites reported in the literature. In addition the Young's modulus of $\mathrm{BP} /$ polymer composites is measured by dynamic mechanical analysis. Díez-Pascual et al. ${ }^{[75]}$ found values of $\mathrm{E}$ at room temperature as high as 2.2 and $3.7 \mathrm{GPa}$ for $\mathrm{BP} / \mathrm{PPS}$ and BP/PEEK, respectively, which means an improvement by 38 and $32 \%$ compared to neat matrices.

As previously discussed in this work, CNTs possess high values of electrical conductivity. Materials with electrical conductivities higher than $10^{-8} \mathrm{~S} / \mathrm{cm}$ are required for electrostatic dissipation, while for electrostatic painting and EMI shielding applications, conductivities greater than $10^{-6}$ to $10^{-1} \mathrm{~S} / \mathrm{cm}$, respectively are required ${ }^{[76-78]}$.

The measured electrical conductivities of traditional $\mathrm{CNT} /$ polymer composites typically ranged from $10^{-5}$ to $10^{-3} \mathrm{~S} / \mathrm{cm}$ above the percolation threshold ${ }^{[76-82]}$. The incorporation of CNTs within a polymer is responsible for creating a CNT network, which allows a transition behavior from a semi-conductive or conductive material. This transition is a phenomenon known as electrical percolation threshold, when conductive pathways are formed at a critical filler concentration in an insulating polymeric matrix. While further increase in CNT content above the percolation threshold can enhance marginally the electrical conductivity of composites, the solution viscosity becomes too high to produce void-free composites when the CNT content is higher than $1.0 \mathrm{wt} . \%$. The incorporation of buckypapers into polymer matrices offers an attractive route to minimize aforementioned issues. As studied by several researches the electrical conductivity of BPs prepared by vacuum filtration process is in the range of 50-6000 $\mathrm{S} / \mathrm{m}^{[58,59,75,83]}$. In a recent work Han et al. ${ }^{[83]}$ measured electrical conductivity of BP/epoxy composites as high as $2000 \mathrm{~S} / \mathrm{m}$. This value is several orders of magnitude higher than the conductivity of conventional CNT/epoxy composites, which due to their preparation method possess a low content of CNTs. This result opens new perspectives in the field of semi conductive materials.

Carbon nanotubes are excellent thermal conductors but their use as fillers in polymeric matrices have not reached the kind of highly thermal conductive composites that one might expect. However, since polymers are usually poor thermal conductors, with thermal conductivity on the order of $0.1 \mathrm{~W} / \mathrm{mK}$, the incorporation of carbon nanotubes still offers significant thermal-conductivity improvements in the resulting CNT/polymer composites ${ }^{[84-87]}$. According to previous works ${ }^{[88]}$, thermal conductivity of epoxy-based composites reinforced with 1.0 vol.\% of MWCNTs increased by more than $100 \%$ reaching a value around $0.5 \mathrm{~W} / \mathrm{mK}$. Díez-Pascual et al. ${ }^{[89]}$ reported similar results for $1.0 \mathrm{wt} . \% \mathrm{SWCNT} / \mathrm{PEEK}$ composites. They found a value around $0.6 \mathrm{~W} / \mathrm{mK}$, which means an increase of $150 \%$ compared to neat polymer matrix.

Since in buckypapers and buckypaper-based composites, CNTs can form dense networks, a high thermal conductivity is expected. Gonnet and collaborators ${ }^{[00]}$ found a value around 18 and $42 \mathrm{~W} / \mathrm{mK}$ for the aligned and the random SWCNTs buckypaper. These values are much lower than the theoretical thermal conductivity predicted for SWCNTs and MWCNTs (6000 and $3000 \mathrm{~W} / \mathrm{mK}$, respectively). This difference can be attributed to the high thermal resistance at nanotube/nanotube junctions ${ }^{[91]}$.

Thermal conductivity of $\mathrm{BP} /$ polymer composites has presented similar results to conventional CNT-based composites. Charpategui et al. ${ }^{[92]}$ prepared BP/epoxy composites where the CNTs concentration was in the range of 35-60 wt.\%. The result revealed a thermal conductivity of $0.43 \mathrm{~W} / \mathrm{mK}$, which is very close to that reported in traditional CNT/epoxy composites $^{[88]}$. This behavior can be attributed to the small thermal conductance of the nanotube-polymer interface, the high interfacial thermal resistance between CNTs and, by a reduction of the number of contact points between $\mathrm{CNTs}^{[88-92]}$, which limit considerably the heat transfer.

Several studies have reported that only small addition of CNTs into polymers can improve the thermal stability of composites significantly, resulting in large increase of thermal decomposition temperatures by about 5-15 ${ }^{\circ} \mathrm{C}^{[93-96]}$. According to literature ${ }^{[97]}$ PPS-based composites reinforced with $5.0 \mathrm{wt} . \%$ of MWCNTs increased thermal decomposition temperature by about $14^{\circ} \mathrm{C}$ compared to neat PPS. Díez-Pascual et al. ${ }^{[98]}$ found similar results for SWCNT reinforced PEEK composites at $1.0 \mathrm{wt}$ \% loading.

Since BP-based composites can be produced with uniform tube dispersion and high CNTs content (up to $60 \mathrm{wt} . \%$ ), the improvement in thermal decomposition properties should be higher to those presented in conventional CNT/polymer composites. Previously Díez-Pascual et al. ${ }^{[99]}$ have manufactured SWCNT BP reinforced PPS and PEEK laminates with a CNT loading of $25 \%$, using hot-press technique. The results revealed an increase of 62 and $45{ }^{\circ} \mathrm{C}$ for BP/PPS and $\mathrm{BP} / \mathrm{PEEK}$ composites, respectively. This exceptional enhancement can be explained by different factors: Firstly, the good impregnation between both matrices and buckypaper improves the interfacial adhesion between them, thus the SWCNT can effectively act as protective barriers to prevent the transport of volatile decomposed products out of BP-based composites during thermal degradation process, resulting in the enhancement of the thermal stability of both polymer matrices. Also, thermal interfacial resistance between the CNTs and the polymer decrease in the presence of chemical 
bonding, resulting to an enhancement of the thermal conductivity, making easy the heat dissipation within the composite. Since CNT concentration is high the barrier effect becomes stronger and the thermal conductivity rises, leading in higher degradation temperatures ${ }^{[93,99]}$. Analogous stability effects have been reported in the literature for $\mathrm{BP} /$ polyimide $^{[91]}$ and $\mathrm{BP} / \mathrm{epoxy}^{\left[{ }^{[6]}\right]}$ composites.

\section{Conclusions}

This review provides a comprehensive overview of the research in carbon nanotube reinforced polymer composites. The main challenge is the development of methods to improve the nanofiller dispersion within the matrix in order to enhance mechanical, electrical and thermal properties of the resulting composites. Giving all this information, carbon nanotube buckypapers have been considered as an option to CNT agglomeration issue, resulting in composites with up to $60 \mathrm{wt} . \%$ of nanofiller. Ultrasonication with the assistance of a dispersant followed by vacuum filtration are the most popular techniques employed to manufacture carbon nanotube buckypapers, which is proved to be an effective way to obtain homogeneous nanotube sheets.

The impregnation between the polymer matrix and buckypaper plays a keyhole during the processing of $\mathrm{BP} /$ polymer composites. Good impregnation leads to an improvement in the interfacial adhesion of the composite, resulting in the upgraded mechanical properties. With regard to electrical and thermal properties, BP-based composites show important and significant results. The high electrical conductivity of the material (around $2000 \mathrm{~S} / \mathrm{m}$ ) is several orders of magnitude higher than the conventional CNT composites, giving them many engineering applications such as electromagnetic interference shielding materials that require conductivities above $10^{-1} \mathrm{~S} / \mathrm{cm}$. Also, the incorporation of buckypapers can improve dramatically the thermal stability of the polymer matrix, resulting in better flame-retardant properties.

\section{Acknowledgements}

This work was supported by Conselho Nacional de Desenvolvimento Científico e Tecnológico (CNPq), project $\mathrm{n}^{\mathrm{o}}$ 502211/2014-8.

\section{References}

1. Chiu, F. C., \& Kao, G. F. (2012). Polyamide 46/multi-walled carbon nanotube nanocomposites with enhanced thermal, electrical, and mechanical properties. Composites. Part A, Applied Science and Manufacturing, 43(1), 208-218. http:// dx.doi.org/10.1016/j.compositesa.2011.10.010.

2. Kim, K. T., \& Jo, W. H. (2011). Non-destructive functionalization of multi-walled carbon nanotubes with naphthalene-containing polymer for Nylon66/multi-walled carbon nanotube composites. Carbon, 49(3), 819-826. http://dx.doi.org/10.1016/j. carbon.2010.10.021.

3. Rahmat, M., \& Hubert, P. (2011). Carbon nanotube-polymer interactions in nanocomposites: a review. Composites Science and Technology, 72(1), 72-84. http://dx.doi.org/10.1016/j. compscitech.2011.10.002.

4. Kallemullah, M., Khan, S. U., \& Kim, J. K. (2012). Effect of surfactant treatment on thermal stability and mechanical properties of CNT/polybenzoxazine nanocomposites.
Composites Science and Technology, 72(16), 72-84. http:// dx.doi.org/10.1016/j.compscitech.2012.08.020.

5. Ajayan, P. M., Stephan, O., Colliex, C., \& Trauth, D. (1994). Aligned carbon canotube arrays formed by cutting a polymer resin—nanotube composite. Science, 265(5176), 1212-1214. PMid:17787587. http://dx.doi.org/10.1126/science.265.5176.1212.

6. Ma, P. C., \& Kim, J. K. (2011). Carbon nanotubes for polymer reinforcement. Boca Raton: CRC Press.

7. Wu, C. S. (2011). Polyester and multiwalled carbon nanotube composites: characterization, electrical conductivity and antibacterial activity. Polymer International, 60(5), 807-815. http://dx.doi.org/10.1002/pi.3022.

8. Yesil, S., \& Bayram, G. (2011). Poly(ethylene terephthalate)/ Carbon Nanotube Composites Prepared With Chemically Treated Carbon Nanotubes. Polymer Engineering and Science, 51(7), 1286-1300. http://dx.doi.org/10.1002/pen.21938.

9. Tang, X. G., Hou, M., Zou, J., Truss, R., \& Zhu, Z. (2012). The creep behavior of poly (vinylidene fluoride)/“budbranched" nanotubes nanocomposites. Composites Science and Technology, 72(14), 1656-1664. http://dx.doi.org/10.1016/j. compscitech.2012.06.025.

10. Ma, P. C., Siddiqui, N. A., Maron, G., \& Kim, J. K. (2010). Dispersion and functionalization of carbon nanotubes for polymer-based nanocomposites: a review. Composites. Part A, Applied Science and Manufacturing, 41(10), 1345-1367. http://dx.doi.org/10.1016/j.compositesa.2010.07.003.

11. Bose, S., Khare, R. A., \& Moldenaers, P. (2010). Assessing the strengths and weaknesses of various types of pre-treatments of carbon nanotubes on the properties of polymer/carbon nanotubes composites: a critical review. Polymer, 51(5), 975993. http://dx.doi.org/10.1016/j.polymer.2010.01.044.

12. Ribeiro, B. (2015). Obtenção e caracterização de compósitos nanoestruturados de poli(sulfeto de fenileno) reforçados com nanotubos de carbono (Tese de doutorado). Universidade Estadual Paulista, Guaratinguetá.

13. Martins-Júnior, P. A., Alcântara, C. E., Resende, R. R., \& Ferreira, A. J. (2013). Carbon nanotubes: directions and perspectives in oral regenerative medicine. Journal of Dental Research, 92(7), 575-583. http://dx.doi.org/10.1177/0022034513483771. PMid:23677650.

14. Green, M. J., Behabtu, N., Pasquali, M., \& Adams, W. W. (2009). Nanotubes as polymers. Polymer, 50(21), 4979-4997. http://dx.doi.org/10.1016/j.polymer.2009.07.044.

15. Grady, B. P. (2011). Carbon-nanotube-polymer composites: manufacture, properties and applications. New Jersey: Wiley.

16. Castillo, F. Y., \& Grady, B. P. (2012). Filler reaggregation and network formation time scale in extruded high-density polyethylene/multiwalled carbon nanotube composites. Polymer Engineering and Science, 52(8), 1761-1774. http:// dx.doi.org/10.1002/pen.23124.

17. Wei, L., Jiang, W., Goh, K., \& Chen, Y. (2013). Mechanical reinforcement of polyethylene using n-alkyl group-functionalized multiwalled carbon nanotubes: Effect of alkyl group carbon chain length and density. Polymer Engineering and Science, 54(2), 336-344. http://dx.doi.org/10.1002/pen.23579.

18. Byrne, M. T., \& Gun'ko, Y. K. (2010). Recent advances in research on carbon nanotube-polymer composites. Advanced Materials, 22(15), 1672-1688. PMid:20496401. http://dx.doi. org/10.1002/adma.200901545.

19. Ren, D., Zheng, S., Wu, F., Yang, W., Liu, Z., \& Yang, M. (2014). Formation and evolution of the carbon black network in polyethylene/carbon black composites: Rheology and conductivity properties. Journal of Applied Polymer Science, 131(7), n/a. http://dx.doi.org/10.1002/app.39953.

20. Zhao, J., Dai, K., Liu, C., Zheng, G., Wang, B., Liu, C., Chen, J., \& Shen, C. (2013). A comparison between strain sensing behaviors of carbon black/polypropylene and carbon nanotubes/ polypropylene electrically conductive composites. Composites. 
Part A, Applied Science and Manufacturing, 48, 129-136. http:// dx.doi.org/10.1016/j.compositesa.2013.01.004.

21. Díez-Pascual, A. M., Ashrafi, B., Naffakh, M., GonzálezDomínguez, J. M., Johnston, A., Simard, B., Martínez, M. T., \& Gómez-Fatou, M. A. (2011). Influence of carbon nanotubes on the thermal, electrical and mechanical properties of poly(ether ether ketone)/glass fiber laminates. Carbon, 49(8), 2817-2833. http://dx.doi.org/10.1016/j.carbon.2011.03.011.

22. Kingston, C., Zepp, R., Andrady, A., Boverhof, D., Fehir, R., Hawkins, D., Roberts, J., Sayre, P., Shelton, B., Sultan, Y., Vejins, V., \& Wohlleben, W. (2014). Release characteristics of selected carbon nanotube polymer composites. Carbon, 68 , 33-57. http://dx.doi.org/10.1016/j.carbon.2013.11.042.

23. Nowack, B., David, R. M., Fissan, H., Morris, H., Shatkin, J., Stintz, M., Zepp, R., \& Brouwer, D. (2013). Potential release scenarios for carbon nanotubes used in composites. Environment International, 59, 1-11. PMid:23708563. http:// dx.doi.org/10.1016/j.envint.2013.04.003.

24. Fujii, M., Zhang, X., Xie, H. Q., Ago, H., Takahashi, K., Ikuta, T., Abe, H., \& Shimizu, T. (2005). Measuring the thermal conductivity of a single carbon nanotube. Physical Review Letters, 95(6), 065502. PMid:16090962. http://dx.doi. org/10.1103/PhysRevLett.95.065502.

25. Choi, T. Y., Poulikakos, D., Tharian, J., \& Sennhauser, U. (2006). Measurement of the thermal conductivity of individual carbon nanotubes by the four-point three-omega method. Nano Letters, 6(8), 1589-1593. PMid:16895340. http://dx.doi. org/10.1021/n1060331v.

26. Díez-Pascual, A. M., Naffakh, M., Marco, C., Ellis, G., \& Gómez-Fatou, M. A. (2012). High-performance nanocomposites based on polyetherketones. Progress in Materials Science, 57(7), 1106-1190. http://dx.doi.org/10.1016/j.pmatsci.2012.03.003.

27. Bose, S., Bhattacharyya, A. R., Kulkarni, A. R., \& Potschke, P. (2009). Electrical, rheological and morphological studies in co-continuous blends of polyamide 6 and acrylonitrilebutadiene-styrene with multiwall carbon nanotubes prepared by melt blending. Composites Science and Technology, 69(3-4), 365-372. http://dx.doi.org/10.1016/j.compscitech.2008.10.024.

28. Menzer, K., Krause, B., Boldt, R., Kretzschamar, B., Weidisch, R., \& Pötschke, P. (2011). Percolation behavior of multiwalled carbon nanotubes of altered length and primary agglomerate morphology in melt mixed isotactic polypropylene-based composites. Composites Science and Technology, 71(16), 19361943. http://dx.doi.org/10.1016/j.compscitech.2011.09.009.

29. Thomas, S. P., Girei, S. A., Atieh, M. A., De, S. K., \& AlJuhani, A. (2012). Rheological behavior of polypropylene nanocomposites at low concentration of surface modified carbon nanotubes. Polymer Engineering and Science, 52(9), 1868-1873. http://dx.doi.org/10.1002/pen.23143.

30. Botelho, E. C., Costa, M. L., Braga, C. I., Burkhart, T., \& Lauke, B. (2013). Viscoelastic behavior of multiwalled carbon nanotubes into phenolic resin. Materials Research, 16(4), 713 720. http://dx.doi.org/10.1590/S1516-14392013005000045.

31. Zhou, K., Gu, S. Y., Zhang, Y. H., \& Ren, J. (2012). Effect of dispersion on rheological and mechanical properties of polypropylene/carbon nanotubes nanocomposites. Polymer Engineering and Science, 52(7), 1484-1494. http://dx.doi. org/10.1002/pen.23098.

32. Penu, C., Hu, G. H., Fernandez, A., Marchal, P., \& Choplin, L. (2012). Rheological and electrical percolation thresholds of carbon nanotube/polymer nanocomposites. Polymer Engineering and Science, 52(10), 2173-2181. http://dx.doi.org/10.1002/ pen. 23162 .

33. Díez-Pascual, A. M., Naffakh, M., Marco, C., \& Ellis, G. (2012). Mechanical and electrical properties of carbon nanotube/poly(phenylene sulphide) composites incorporating polyetherimide and inorganic fullerene-like nanoparticles.
Composites. Part A, Applied Science and Manufacturing, 43(4), 603-612. http://dx.doi.org/10.1016/j.compositesa.2011.12.026.

34. Pereira, A. C. (2011). Estudo da cinética de cura e das propriedades térmicas da resina benzoxazina e de seus compósitos nanoestruturados (Dissertação de mestrado). Universidade Estadual Paulista, Guaratinguetá.

35. Lu, K. L., Lago, R. M., Chen, Y. K., Green, M. L. H., Harris, P. J. F., \& Tsang, S. C. (1996). Mechanical damage of carbon nanotubes by ultrasound. Carbon, 34(6), 814-816. http://dx.doi. org/10.1016/0008-6223(96)89470-X.

36. Huang, Y. Y., \& Terentjev, E. M. (2012). Dispersion of carbon nanotubes: mixing, sonication, stabilization, and composite properties. Polymers, 4(1), 275-295. http://dx.doi.org/10.3390/ polym 4010275 .

37. Inam, F., Reece, M. J., \& Pejis, T. (2012). Shortened carbon nanotubes and their influence on the electrical properties of polymer nanocomposites. Journal of Composite Materials, 46(11), 1313-1322. http://dx.doi.org/10.1177/0021998311418139.

38. Cha, J., Jin, S., Shim, J. H., Park, C. S., Ryu, H. J., \& Hong, S. H. (2016). Functionalization of carbon nanotubes for fabrication of CNT/epoxy nanocomposites. Materials \& Design, 95, 1-8. http://dx.doi.org/10.1016/j.matdes.2016.01.077.

39. Sahoo, N. G., Rana, S., Cho, J. W., Li, L., \& Chan, S. W. (2010). Polymer nanocomposites based on functionalized carbon nanotubes. Progress in Polymer Science, 35(7), 837 867. http://dx.doi.org/10.1016/j.progpolymsci.2010.03.002.

40. Saito, T., Matsushige, K., \& Tanaka, K. (2002). Chemical treatment and modification of multiwalled carbon nanotubes. Physica B, Condensed Matter, 323(1-4), 280-283. http://dx.doi. org/10.1016/S0921-4526(02)00999-7.

41. Bikiaris, D., Vassiliou, A., Chrissafis, K., Paraskevopoulos, K. M., Jannakoudakis, A., \& Docoslis, A. (2008). Effect of acid treated multiwalled carbon nanotubes on the mechanical, permeability, thermal properties and thermo-oxidative stability of isotactic polypropylene. Polymer Degradation \& Stability, 93(5), 952-967. http://dx.doi.org/10.1016/j. polymdegradstab.2008.01.033.

42. Bilalis, P., Katsigiannopoulos, D., Avgeropoulos, A., \& Sakellariou, G. (2014). Non-covalent functionalization of carbon nanotubes with polymers. RSC Advances, 4(6), 29112934. http://dx.doi.org/10.1039/C3RA44906H.

43. Morishita, T., Matsushita, M., Katagiri, Y., \& Fukumori, K. (2010). Noncovalent functionalization of carbon nanotubes with maleimide polymers applicable to high-melting polymerbased composites. Carbon, 48(8), 2308-2316. http://dx.doi. org/10.1016/j.carbon.2010.03.007.

44. Spitalsky, Z., Tasis, D., Papagelis, K., \& Galiotis, C. (2010). Carbon nanotube-polymer composites: Chemistry, processing, mechanical and electrical properties. Progress in Polymer Science, 35(3), 357-401. http://dx.doi.org/10.1016/j. progpolymsci.2009.09.003.

45. Hill, D. E., Lin, Y., Rao, A. M., Allard, L. F., \& Sun, Y. P (2002). Functionalization of carbon nanotubes with polystyrene. Macromolecules, 35(25), 9466-9471. http://dx.doi.org/10.1021/ ma020855r.

46. Díez-Pascual, A. M., Naffakh, M., Gómez, M. A., Marco, C., Ellis, G., González-Domínguez, J. M., Ansón, A., Martinez, M. T., Martínez-Rubi, Y., Simard, B., \& Ashrafi, B. (2009). The influence of a compatibilizer on the thermal and dynamic mechanical properties of PEEK/carbon nanotube composites. Nanotechnology, 20(31), 315707-315720. PMid:19597256. http://dx.doi.org/10.1088/0957-4484/20/31/315707.

47. Geng, Y., Liu, M. Y., Li, J., Shi, X. M., \& Kim, J. K. (2008). Effects of surfactant treatment on mechanical and electrical properties of CNT/epoxy nanocomposites. Composites. Part A, Applied Science and Manufacturing, 39(12), 1876-1883. http://dx.doi.org/10.1016/j.compositesa.2008.09.009. 
48. Sohrabi, B., Poorgholami-Bejarpasi, N., \& Nayeri, N. (2014). Dispersion of carbon nanotubes using mixed surfactants: Experimental and molecular dynamics simulation studies. The Journal of Physical Chemistry B, 118(11), 3094-3103. PMid:24555914. http://dx.doi.org/10.1021/jp407532j.

49. Aldalbahi, A., \& in het Panhuis, M. (2012). Electrical and mechanical characteristics of buckypapers and evaporative cast films prepared using single and multiwalled carbon nanotubes and the biopolymer carrageenan. Carbon, 50(3), 1197-1208. http://dx.doi.org/10.1016/j.carbon.2011.10.034.

50. Wang, Z., Liang, Z., Wang, B., Zhang, C., \& Kramer, L. (2004). Processing and property investigation of single-walled carbon nanotube (SWNT) buckypaper/epoxy resin matrix nanocomposites. Composites. Part A, Applied Science and Manufacturing, 35(10), 1225-1232. http://dx.doi.org/10.1016/j. compositesa.2003.09.029.

51. Wang, S., Liang, Z., Pham, G., Park, Y. B., Wang, B., Zhang, C., Kramer, L., \& Funchess, P. (2007). Controlled nanostructure and high loading of single-walled carbon nanotubes reinforced polycarbonate composite. Nanotechnology, 18(9), 095708. http://dx.doi.org/10.1088/0957-4484/18/9/095708.

52. Wang, S., Haldane, D., Liang, R., Smithyman, J., Zhang, C., \& Wang, B. (2013). Nanoscale infiltration behavior and through-thickness permeability of carbon nanotube buckypapers. Nanotechnology, 24(1), 015704. PMid:23221271. http://dx.doi. org/10.1088/0957-4484/24/1/015704

53. Vohrer, U., Kolaric, I., Haque, M. H., Roth, S., \& DetlaffWeglikowska, U. (2004). Carbon nanotube sheets for the use as artificial muscles. Carbon, 42(5-6), 1159-1164. http:// dx.doi.org/10.1016/j.carbon.2003.12.044.

54. Zhu, W., Zheng, J. P., Liang, R., Wang, B., Zhang, C., Walsh, S., Au, G., \& Plichta, E. J. (2008). Highly-efficient buckypaperbased electrodes for PEMFC. ESC Transactions, 16(2), 16151626. http://dx.doi.org/10.1149/1.2982001

55. Giubileo, F., Di Bartolomeo, A., Sarno, M., Altavilla, C., Santandrea, S., Ciambelli, P., \& Cucolo, A. M. (2012). Field emission properties of as-grown multiwalled carbon nanotube films. Carbon, 50(1), 163-169. http://dx.doi.org/10.1016/j. carbon.2011.08.015.

56. Wu, Q., Zhu, W., Zhang, C., Liang, Z., \& Wang, B. (2010). Study of fire retardant behavior of carbon nanotube membranes and carbon nanofiber paper in carbon fiber reinforced epoxy composites. Carbon, 48(6), 1799-1806. http://dx.doi. org/10.1016/j.carbon.2010.01.023.

57. Sears, K., Dumee, L., Schutz, J., She, M., Huynh, C., Hawkins, S., Duke, M., \& Gray, S. (2010). Recent developments in carbon nanotube membranes for water purification and gas separation. Materials, 3(1), 129-149. http://dx.doi.org/10.3390/ ma3010127.

58. Pham, G., Park, Y. B., Wang, S., Liang, Z., Wang, B., Zhang, C., Funchess, P., \& Kramer, L. (2008). Mechanical and electrical properties of polycarbonate nanotube buckypaper composite sheets. Nanotechnology, 19(32), 325705. PMid:21828827. http://dx.doi.org/10.1088/0957-4484/19/32/325705.

59. Lima, A. M. F., Castro, V. G., Borges, R. S., \& Silva, G. G. (2012). Electrical conductivity and thermal properties of functionalized carbon nanotubes/polyurethane composites. Polimeros: Ciência e Tecnologia, 22(2), 117-124. http://dx.doi. org/10.1590/S0104-14282012005000017.

60. Chapartegui, M., Barcena, J., Irastorza, X., Elizetxea, C., Fernadez, M., \& Santamaria, A. (2012). Analysis of the conditions to manufacture a MWCNT buckypaper/benzoxazine nanocomposite. Composites Science and Technology, 72(4), 489-497. http://dx.doi.org/10.1016/j.compscitech.2011.12.001.

61. Zhang, J., \& Jiang, D. (2012). Influence of geometries of multiwalled carbon nanotubes on the pore structures of Buckypaper. Composites. Part A, Applied Science and Manufacturing, 43(3), 469-474. http://dx.doi.org/10.1016/j.compositesa.2011.11.016.
62. Yang, J., Xu, T., Lu, A., Zhang, Q., Tan, H., \& Fu, Q. (2009). Preparation and properties of poly (p-phenylene sulfide)/ multiwall carbon nanotube composites obtained by melt compounding. Composites Science and Technology, 69(2), 147-153. http://dx.doi.org/10.1016/j.compscitech.2008.08.030.

63. Kumar, S., Li, B., Caceres, S., Maguire, R. G., \& Zhong, W. H. (2009). Dramatic property enhancement in polyetherimide using low-cost commercially functionalized multiwalled carbon nanotubes via a facile solution processing method. Nanotechnology, 20(46), 465708. PMid:19847036. http:// dx.doi.org/10.1088/0957-4484/20/46/465708.

64. Zhang, J., Kong, L. B., Wang, B., Luo, Y. C., \& Kang, L. (2009). In-situ electrochemical polymerization of multiwalled carbon nanotube/polyaniline composite films for electrochemical supercapacitors. Synthetic Metals, 159(3-4), 260-266. http:// dx.doi.org/10.1016/j.synthmet.2008.09.018.

65. Song, L., Zhang, H., Zhang, Z., \& Xie, S. (2007). Processing and performance improvements of SWNT paper reinforced PEEK nanocomposites. Composites. Part A, Applied Science and Manufacturing, 38(2), 388-392. http://dx.doi.org/10.1016/j. compositesa.2006.03.007.

66. Lahiff, E., Leahy,R., Coleman, J. N., \& Blau, W. J. (2006). Physical properties of novel free-standing polymer-nanotube thin films. Carbon, 44(8), 1525-1529. http://dx.doi.org/10.1016/j. carbon.2005.12.018.

67. Coleman, J. N., Blau, W. J., Dalton, A. B., Muñoz, E., Collins, S., Kim, B. G., Razal, J., Selvidge, M., Vieiro, G., \& Baughman, R. (1682-1684). Improving the mechanical properties of single-walled carbon nanotube sheets by intercalation of polymeric adhesives. Applied Physics Letters, 82(11). http:// dx.doi.org/10.1063/1.1559421.

68. Che, J., Chen, P., \& Chan-Park, M. B. (2013). High-strength carbon nanotube buckypaper composites as applied to freestanding electrodes for supercapacitors. Journal of Materials Chemistry. A, Materials for Energy and Sustainability, 1(12), 4057-4066. http://dx.doi.org/10.1039/c3ta01421e.

69. Wang, X., Lu, S., Ma, K., Xiong, X., Zhang, H., \& Xu, M. (2015). Tensile strain sensing of buckypaper and buckypaper composites. Materials \& Design, 88, 414-419. http://dx.doi. org/10.1016/j.matdes.2015.09.035.

70. Steiner, S., Busato, S., \& Ermanni, P. (2012). Mechanical properties and morphology of papers prepared from singlewalled carbon nanotubes functionalized with aromatic amides. Carbon, 50(5), 1713-1719. http://dx.doi.org/10.1016/j. carbon.2011.12.001.

71. Berhan, L., Yi, Y. B., Sastry, A. M., Munoz, E., Selvidge, M., \& Baughman, R. (2004). Mechanical properties of nanotube sheets: Alterations in joint morphology and achievable moduli in manufacturable materials. Journal of Applied Physics, 95(8), 4335-4345. http://dx.doi.org/10.1063/1.1687995.

72. Trakakis, J., Tasis, D., Aggelopoulos, C., Parthenios, J., Galiotis, C., \& Papagelis, K. (2013). Open structured in comparison with dense multiwalled carbon nanotube buckypapers and their composites. Composites Science and Technology, 77, 52-59. http://dx.doi.org/10.1016/j.compscitech.2013.01.003.

73. Han, J., Zhang, H., Chen, M., Wang, G., \& Zhang, Z. (2014). CNT buckypaper/thermoplastic polyurethane composites with enhanced stiffness, strength and toughness. Composites Science and Technology, 103, 63-71. http://dx.doi.org/10.1016/j. compscitech.2014.08.015.

74. Ashrafi, B., Guan, J., Mirjalili, V., Hubert, P., Simard, B., \& Johnston, A. (2010). Correlation between Young's modulus and impregnation quality of epoxy-impregnated SWCNT buckypaper. Composites. Part A, Applied Science and Manufacturing, 41(9), 1184-1191. http://dx.doi.org/10.1016/j. compositesa.2010.04.018.

75. Díez-Pascual, A. M., Guan, J., Simard, B., \& Gómez-Fatou, M. A. (2012). Poly(phenylene sulphide) and poly(ether ether 
ketone) composites reinforced with single-walled carbon nanotube buckypaper: II - Mechanical properties, electrical and thermal conductivity. Composites. Part A, Applied Science and Manufacturing, 43(6), 1007-1015. http://dx.doi.org/10.1016/j. compositesa.2011.11.003.

76. Díez-Pascual, A. M., Naffakh, M., Marco, C., \& Ellis, G. (2012). Mechanical and electrical properties of carbon nanotube/poly(phenylene sulphide) composites incorporating polyetherimide and inorganic fullerene-like nanoparticles. Composites. Part A, Applied Science and Manufacturing, 43(4), 603-612. http://dx.doi.org/10.1016/j.compositesa.2011.12.026.

77. Chiu, F.-C., \& Cao, G.-F. (2012). Polyamide 46/multiwalled carbon nanotube nanocomposites with enhanced thermal, electrical, and mechanical properties. Composites. Part A, Applied Science and Manufacturing, 43(1), 208-218. http:// dx.doi.org/10.1016/j.compositesa.2011.10.010.

78. Liebscher, M., Tzounis, L., Potschke, P., \& Heinrich, G. (2013). Influence of the viscosity ratio in PC/SAN blends filled with MWCNTs on the morphological, electrical, and melt rheological properties. Polymer, 54(25), 6801-6808. http://dx.doi.org/10.1016/j.polymer.2013.10.040.

79. Bouchard, J., Cayla, A., Devaux, E., \& Campagne, C. (2013). Electrical and thermal conductivities of multiwalled carbon nanotubes-reinforced high performance polymer nanocomposites. Composites Science and Technology, 86, 177-184. http://dx.doi. org/10.1016/j.compscitech.2013.07.017.

80. Ribeiro, B., Botelho, E. C., \& Costa, M. L. (2015). Estudo das propriedades elétricas e térmicas de compósitos nanoestruturados de poli(sulfeto de fenileno) reforçados com nanotubos de carbono. Polímeros: Ciência e Tecnologia, 25(1), 94-100. http://dx.doi.org/10.1590/0104-1428.1728.

81. Krause, B., Boldt, R., Häußler, L., \& Pötschke, P. (2015). Ultralow percolation threshold in polyamide 6.6/MWCNT composites. Composites Science and Technology, 114, 119. 125. http://dx.doi.org/10.1016/j.compscitech.2015.03.014.

82. Noh, Y. J., Pak, S. Y., Hwang, S. W., Hwanh, J. Y., Kim, S. Y., \& Youn, J. R. (2013). Enhanced dispersion for electrical percolation behavior of multiwalled carbon nanotubes in polymer nanocomposites using simple powder mixing and in situ polymerization with surface treatment of the fillers. Composites Science and Technology, 89, 29-37. http://dx.doi. org/10.1016/j.compscitech.2013.09.013.

83. Han, J. H., Zhang, H., Chu, P. F., Imani, A., \& Zhang, Z. (2015). Friction and wear of high electrical conductive carbon nanotube buckypaper/epoxy composites. Composites Science and Technology, 114, 1-10. http://dx.doi.org/10.1016/j. compscitech.2015.03.012.

84. Wang, S., Liang, R., Wang, B., \& Zhang, X. (2009). Dispersion and thermal conductivity of carbon nanotube composites. Carbon, 47(1), 53-57. http://dx.doi.org/10.1016/j.carbon.2008.08.024.

85. Kwon, S. Y., Kwon, I. M., Kim, Y. G., Lee, S., \& Seo, Y. S. (2013). A large increase in the thermal conductivity of carbon nanotube/polymer composites produced by percolation phenomena. Carbon, 55, 285-290. http://dx.doi.org/10.1016/j. carbon.2012.12.063.

86. Han, Z., \& Fina, A. (2011). Thermal conductivity of carbon nanotubes and their polymer nanocomposites: a review. Progress in Polymer Science, 36(7), 914-944. http://dx.doi. org/10.1016/j.progpolymsci.2010.11.004.

87. Marconnet, A. M., Yamamoto, M., Panzer, M. A., Wardle, B. L., \& Goodson, K. E. (2011). Thermal conduction in aligned carbon nanotube-polymer nanocomposites with high packing density. ACS Nano, 5(6), 4818-4825. PMid:21598962. http:// dx.doi.org/10.1021/nn200847u.

88. Yang, S. Y., Ma, C. M., Teng, C. C., Huang, Y. W., Liao, S. H., Huang, Y. L., Tien, H. W., Lee, T. M., \& Chiou, K. C. (2010). Effect of functionalized carbon nanotubes on the thermal conductivity of epoxy composites. Carbon, 48(3), 592-603. http://dx.doi.org/10.1016/j.carbon.2009.08.047.

89. Díez-Pascual,A. M., Martínez, G., Martínez, M. T., \& Goméz, M. A. (2010). Novel nanocomposites reinforced with hydroxylated poly(ether ether ketone)-grafted carbon nanotubes. Journal of Materials Chemistry, 20(38), 8247-8256. http://dx.doi. org/10.1039/C0JM01531H.

90. Gonnet, P., Liang, Z., Choi, E. S., Kadambala, R. S., Zhang, C., Brooks, J. S., Wang, B., \& Kramer, L. (2006). Thermal conductivity of magnetically aligned carbon nanotube buckypapers and nanocomposites. Current Applied Physics, 6(1), 119-122. http://dx.doi.org/10.1016/j.cap.2005.01.053.

91. Fu, X., Zhang, C., Liu, T., Liang, R., \& Wang, B. (2010). Carbon nanotube buckypaper to improve fire retardancy of high-temperature/high-performance polymer composites. Nanotechnology, 21(23), 235701-235709. PMid:20463386. http://dx.doi.org/10.1088/0957-4484/21/23/235701.

92. Chapartegui, M., Barcena, J., Irastorza, X., Elizetxea, C., Fiamegkou, E., Kostopoulos, V., \& Santamaria, A. (2012). Manufacturing, characterization and thermal conductivity of epoxy and benzoxazine multiwalled carbon nanotube buckypaper composites. Journal of Composite Materials, 47(14), 1705 1715. http://dx.doi.org/10.1177/0021998312450929.

93. Ribeiro, B., Botelho, E. C., \& Costa, M. L. (2014). Estudo da cinética de decomposição de compósitos nanoestruturados de poli (sulfeto de fenileno) reforçados com nanotubos de carbono. Polímeros: Ciência e Tecnologia, 24(6), 720-725. http://dx.doi.org/10.1590/0104-1428.1698.

94. Chrissafis, K., \& Bikiaris, D. (2011). Can nanoparticles really enhance thermal stability of polymers? Part I: An overview on thermal decomposition of addition polymers. Thermochimica Acta, 523(1-2), 1-24. http://dx.doi.org/10.1016/j.tca.2011.06.010.

95. Chen, S., Yu, H., Ren, W., \& Zhang, Y. (2009). Thermal degradation behavior of hydrogenated nitrile-butadiene rubber (HNBR)/clay nanocomposite and HNBR/clay/carbon nanotubes nanocomposites. Thermochimica Acta, 491(1-2), 103-108. http://dx.doi.org/10.1016/j.tca.2009.03.010.

96. Kim, J. Y., Park, W. S., \& Kim, S. H. (2009). Thermal decomposition behavior of carbon-nanotube- reinforced poly(ethylene 2,6-naphthalate) nanocomposites. Journal of Applied Polymer Science, 113(3), 2008-2017. http://dx.doi. org/10.1002/app.30297.

97. Yu, S., Wong, W. M., Hu, X., \& Juay, Y. K. (2009). The characteristics of carbon nanotube-reinforced poly(phenylene sulfide) nanocomposites. Journal of Applied Polymer Science, 113(6), 3477-3483. http://dx.doi.org/10.1002/app.30191.

98. Díez-Pascual, A. M., Naffakh, M., González-Domínguez, J. M., Ansón, A., Martínez-Rúbi, Y., Martínez, M. T., Simard, B., \& Gómez, M. A. (2010). High performance PEEK/carbon nanotube composites compatibilized with polysulfones-I. Structure and thermal properties. Carbon, 48(12), 3485-3499. http://dx.doi.org/10.1016/j.carbon.2010.05.046.

99. Díez-Pascual, A. M., Guan, J., Simard, B., \& Gómez-Fatou, M. A. (2012). Poly(phenylene sulphide) and poly(ether ether ketone) composites reinforced with single-walled carbon nanotube buckypaper: I - Structure, thermal stability and crystallization behavior. Composites. Part A, Applied Science and Manufacturing, 43(6), 997-1006. http://dx.doi.org/10.1016/j. compositesa.2011.11.002. 